\title{
Mode of delivery is not associated with celiac disease
}

This article was published in the following Dove Press journal:

Clinical Epidemiology

\author{
Stine Dydensborg Sander ${ }^{1,2}$ \\ Anne Vinkel Hansen ${ }^{3,4}$ \\ Ketil Størdal ${ }^{5,6}$ \\ Anne-Marie Nybo \\ Andersen ${ }^{3}$ \\ Joseph A Murray ${ }^{7}$ \\ Steffen Husby ${ }^{1,2}$
}

'Hans Christian Andersen Children's Hospital, Odense University

Hospital, Odense, Denmark; ${ }^{2}$ Institute of Clinical Research, Faculty of Health Science, University of Southern Denmark, Odense, Denmark; ${ }^{3}$ Department of Public Health, University of Copenhagen, Copenhagen, Denmark; ${ }^{4}$ Statistics Denmark, Copenhagen, Denmark; ${ }^{5}$ Department of Child Health, Norwegian Institute of Public Health, Oslo, Norway; ${ }^{6}$ Department of Pediatrics, Ostfold Hospital Trust, Grålum, Norway; ${ }^{7}$ Division of Gastroenterology and Hepatology, Mayo Clinic, Rochester, MN, USA

Correspondence: Steffen Husby Hans Christian Andersen Children's Hospital, Odense University Hospital, Kløvervænget 23C, 5000 Odense C, Denmark

Tel $+45654 \mid 2090$

Fax +45 6591 1862

Email steffen.husby@rsyd.dk
Purpose: The purpose of this study was to investigate the association between mode of delivery and the risk of celiac disease in two large population-based birth cohorts with different prevalence of diagnosed celiac disease.

Patients and methods: This is an observational register-based cohort study using two independent population cohorts. We used data from administrative registers and health administrative registers from Denmark and Norway and linked the data at the individual level. We included all children who were born in Denmark from January 1, 1995 to December 31, 2010 and all children who were born in Norway from January 1, 2004 to December 31, 2012.

Results: We included 1,051,028 children from Denmark. Cesarean sections were registered for 196,512 children (18.9\%). Diagnosed celiac disease was registered for 1,395 children $(0.13 \%)$. We included 537,457 children from Norway. Cesarean sections were registered for 90,128 children (16.8\%). Diagnosed celiac disease was registered for 1,919 children $(0.35 \%)$. We found no association between the mode of delivery and the risk of diagnosed celiac disease. The adjusted odds ratio for celiac disease for children delivered by any type of cesarean section compared to vaginal delivery was 1.11 (95\% CI: 0.96-1.29) in the Danish cohort and 0.96 (95\% CI: 0.84-1.09) in the Norwegian cohort. The adjusted odds ratio for celiac disease for children delivered by elective cesarean section compared to vaginal delivery was 1.20 (95\% CI: $1.00-1.43)$ in the Danish cohort and 0.96 (95\% CI: 0.79-1.17) in the Norwegian cohort.

Conclusion: In this large registry-based study, mode of delivery was not associated with an increased risk of diagnosed celiac disease.

Keywords: cesarean section, autoimmunity, epidemiology, administrative health register

\section{Introduction}

Celiac disease is a chronic immune-mediated systemic disorder that is elicited in genetically susceptible individuals by gluten and related prolamins. ${ }^{1}$ Over the last 50 years, the prevalence of celiac disease has increased by four- to fivefold, ${ }^{2,3}$ most likely due to improved diagnosis and increased awareness of atypical presentations as well as an increase in the actual prevalence. , $^{2,45}$

The presence of one of the human leukocyte antigens (HLA) DQ2 or DQ8 is a prerequisite to develop celiac disease. ${ }^{6}$ About $30 \%$ of the general population carry these genes ${ }^{7}$ but only about $1 \%$ of the population develop celiac disease. Environmental exposures, other than gluten, that contribute to the development of celiac disease are still to be clarified. ${ }^{8}$ Several perinatal factors including infant feeding have been suggested, but the evidence is conflicting. ${ }^{9,10}$ 
Concurrent with the increasing prevalence of celiac disease, the prevalence of cesarean sections has increased. ${ }^{11}$ Studies have indicated an association between cesarean section and an increased risk of celiac disease, ${ }^{12-14}$ especially elective cesarean section, ${ }^{15}$ but the conclusions of other studies on this subject are contradictory. ${ }^{16-20}$

Cesarean section has prolonged consequences for the intestinal microbiota. ${ }^{21}$ It is hypothesized that the possible increased risk of celiac disease is a consequence of alterations in the intestinal microbiota in the first year of life leading to a dysregulation of the immune system that increases the risk of celiac disease. ${ }^{22}$ Studies have suggested that individuals with celiac disease have a different microbiota compared to healthy controls. ${ }^{23-25}$ Alterations in the gut microbiota have been associated with other immunemediated diseases including type 1 diabetes $^{26}$ and asthma. ${ }^{27,28}$ Emergency cesarean section may be initiated after rupture of the amniotic sac and thus these babies may be exposed to maternal vaginal microbiota while babies born by elective cesarean section are not exposed to maternal vaginal microbiota.

The objective of this study was to investigate the association between cesarean section and the risk of celiac disease in two large independent birth cohorts derived from populations with different prevalence of diagnosed celiac disease.

\section{Patients and methods}

This study is an observational register-based cohort study in two independent population-covering cohorts, one from Denmark and one from Norway. We used data from administrative registers and health administrative registers. A unique personal identification number is assigned to everyone who is born or lives in Denmark or Norway. All registrations are linked to these numbers and they enabled linkage of data at the individual level. Based on data availability, we included all children who were born in Denmark from January 1, 1995 to December 31, 2010 and all children who were born in Norway from January 1, 2004 to December 31, 2012. We estimate that about $7 \%$ of the Norwegian study population was included in the Norwegian Mother and Child Cohort Study published by Emilsson et al. ${ }^{29}$ The outcome was diagnosed celiac disease (International Classification of Diseases 10th revision [ICD-10] K90.0). The main exposure was mode of delivery (vaginal or cesarean section). In subanalyses, we distinguished between elective and emergency cesarean section.

\section{Registers and variables Denmark}

The Danish Civil Registration System contains information on all residents in Denmark, including date of birth, sex, identity of parents, and date of death or emigration. Maternal country of birth was registered as mother's country of birth for immigrants and as the maternal grandmother's country of birth for second-generation immigrants. ${ }^{30}$

The Danish National Patient Register contains data from all inpatients and outpatients admitted to Danish hospitals. Diagnoses are registered in accordance with ICD-10 from 1994 onwards. ${ }^{31,32}$ We received data registered in the Danish National Patient Register until May 6, 2015. To identify children with celiac disease, we included all registrations of celiac disease (ICD-10 K90.0) and validated the diagnoses with duodenal biopsies registered in the Danish Database of Pathology (http://www.patobank.dk) and celiac diseasespecific antibodies and HLA genotypes from medical records. We considered the diagnosis to be validated if a duodenal biopsy compatible with celiac disease (Marsh 2-3) was registered in the Danish Database of Pathology (77\% of the children with a validated diagnosis) or if positive endomysium antibody immunoglobulin A ( $\operatorname{IgA}$ ) or antitissue transglutaminase $2 \operatorname{IgA}$ at 10 or more times the upper limit of normal was registered in the medical record ( $76 \%$ of the children with a validated diagnosis). The positive predictive value of a registration with celiac disease in the Danish National Patient Register was 66\% (95\% CI: 64\%-68\%). Details about this validation are published elsewhere. ${ }^{33}$

For all children we included information on the following diseases known to be associated with celiac disease (see the section "Sensitivity analyses"): type 1 diabetes (ICD-10 E10, E14), autoimmune thyroid disease (ICD-10 E03.9, E05, E06.3), autoimmune hepatitis (ICD-10 K75.4, K73.2), juvenile rheumatoid arthritis (ICD-10 M08.0), Down's syndrome (ICD-10 Q90), and Turner's syndrome (ICD-10 Q96). We used the date of the first registration as the date of diagnosis.

To identify children registered with chronic abdominal pain in the absence of registration of a gastrointestinal disease (see the section "Post hoc analyses"), we retrieved diagnoses of abdominal pain (ICD-10 R10.1, R10.3, R10.4, or R10.8) and gastrointestinal disease (ICD-10 K*).

We included information on maternal autoimmune diseases (thyroid disease [ICD-10 E05.0, E06.3, O9.92B, or O99.2C], rheumatoid arthritis [ICD-10 M05 or M06], type 1 diabetes [ICD-10 E10 or O24.0], and celiac disease [ICD-10 K90.0]) if the disease was registered before the birth of the child that is included in the study (see the section "Sensitivity analyses").

The Danish Medical Birth Register contains detailed information on all pregnancies and births in Denmark. ${ }^{34}$ We included variables for birthweight, gestational age and maternal age, parity, smoking, prepregnancy body mass 
index (BMI) (available from 2004), and maternal request for cesarean section (available from 2002).

The Danish Population's Education Register contains information on the highest level of completed education and ongoing education. ${ }^{35}$ We used information on maternal education level from the year of each child's birth.

\section{Norway}

The Norwegian National Patient Register contains data from all Norwegian government-owned hospitals and outpatient clinics. Diagnoses are recorded in accordance with ICD-10. ${ }^{36}$ We received data registered in the Norwegian National Patient Register until December 31, 2013. We considered all children with two or more registrations of celiac disease (ICD-10 K90.0) as having diagnosed celiac disease. The use of two or more registrations ensures greater validity. ${ }^{13,29}$ The data did not include the exact dates of registration but are available as cumulative data for each year. Data from 2004 to 2008 are further accumulated precluding exact year of diagnosis.

The Norwegian Medical Birth Register contains detailed information on all pregnancies and births in Norway. ${ }^{37} \mathrm{We}$ included variables for sex, month and year of birth, birthweight, gestational age and maternal age, parity, smoking, and diabetes mellitus diagnosed before pregnancy (excluding gestational diabetes mellitus). The exact dates of birth were not available because of Norwegian government regulations on data security.

Maternal educational level was derived from Statistics Norway (http://www.ssb.no/en). We used information from the year of each child's birth.

The categorization of variables was based on commonly used groupings, as indicated in Table 1.

\section{Statistics}

\section{Statistical methods}

The data were analyzed using logistic regression. All the analyses were performed with complete case analysis and they were adjusted for year of birth to take into account differences in follow-up times and the prevalence of cesarean sections and celiac disease. We used robust cluster variance estimation to take into account siblings (with the same mother). We carried out subanalyses for type of cesarean section (elective or emergency), with vaginal delivery as the reference category.

The data were analyzed using three main models to accommodate the uncertainty of potential confounders. In model 1, we adjusted for year of birth and sex. In model 2, we added maternal age, education, and parity. In model 3, we added gestational age and weight for gestational age $(\leq 10$ th percentile, 10 th-90th percentile, or $\geq 90$ th percentile). Information on maternal smoking during pregnancy was missing for a large proportion of children, so we analyzed the effect of smoking separately.

A 95\% CI for the odds ratio (OR) that excluded 1.00 was considered statistically significant. All analyses were conducted using Stata version 14 (StataCorp LP) statistical software.

\section{Sensitivity analyses}

We examined the effect of the potential confounders that were only available in the Danish cohort: maternal country of birth, maternal prepregnancy BMI, and maternal autoimmune diseases diagnosed before the birth of the child. We stratified the children for early or late diagnosis ( $<2$ or $\geq 2$ years of age) because the presentation of celiac disease differs with age. We stratified for the presence of an associated comorbidity in the child (yes or no). Children with an associated disease are recommended screening for celiac disease and thus we expect the proportion of diagnosed compared to undiagnosed celiac disease to be higher in these children compared to the general population.

In a sensitivity analysis to examine the effect of model choice, we analyzed the Danish data using Cox regression with follow-up time from 6 months of age (the recommended age for introduction of gluten to the diet) to the first of any of the following events: diagnosis, emigration, death, or May 1, 2015. Five children were diagnosed before 6 months of age and were excluded from the analysis. We adjusted for year of birth, sex, gestational age, weight for gestational age and maternal age, education, and parity. Further, having an associated comorbidity along with celiac disease was analyzed as a competing risk.

To address the issue of missing data, models 1-3 and model 3 with adjustment for maternal smoking were also analyzed with imputation for missing data. Missing data in a variable used in the analysis was seen in $1 \%$ of the Danish children (5\% when including smoking) and 5\% of the Norwegian children (20\% when including smoking). For the sake of simplicity, variables with $<2 \%$ missing data (i.e., the variables for mode of delivery, gestational age, weight for gestational age and maternal age, and parity) were dealt with using single imputation with the mode of the variable. Imputation for maternal smoking (Denmark: 4\% missing, Norway: 17\% missing) and education (Denmark: 3\% missing, Norway: 4\% missing) was carried out using multiple imputation by chained equations. We made 20 imputations ${ }^{38}$ 
Table I Distribution of potential confounders according to celiac disease diagnosis

\begin{tabular}{|c|c|c|c|c|}
\hline \multirow[t]{2}{*}{ Characteristic } & \multicolumn{2}{|l|}{ Denmark } & \multicolumn{2}{|l|}{ Norway } \\
\hline & $\begin{array}{l}\text { No celiac disease, } \\
\text { No }\left(\%^{a}\right)(n=1,049,633)\end{array}$ & $\begin{array}{l}\text { Celiac disease, } \\
\text { No }\left(\%^{\mathrm{a}}\right)(\mathrm{n}=1,395)\end{array}$ & $\begin{array}{l}\text { No celiac disease, } \\
\text { No }\left(\%^{\mathrm{a}}\right)(n=535,538)\end{array}$ & $\begin{array}{l}\text { Celiac disease, } \\
\text { No }(\%)(n=I, 9 \mid 9)\end{array}$ \\
\hline \multicolumn{5}{|l|}{ Mode of delivery } \\
\hline Vaginal delivery & $841,916(81.1)$ & I, I $20(80.9)$ & $445,698(83.2)$ & I,63I (85.0) \\
\hline Cesarean section & $196,248(18.9)$ & $264(19.1)$ & $89,840(16.8)$ & $288(15.0)$ \\
\hline Emergency ${ }^{\mathrm{b}}$ & $92,854(9.0)$ & $118(8.5)$ & $54,799(10.2)$ & I7I (8.9) \\
\hline Elective $^{\mathrm{b}}$ & $103,213(9.9)$ & $146(10.6)$ & $34,612(6.5)$ & II $6(6.0)$ \\
\hline Missing & 11,469 & II & 0 & 0 \\
\hline \multicolumn{5}{|l|}{ Year of birth } \\
\hline $1995-1997$ & $204,878(19.5)$ & $285(20.4)$ & - & - \\
\hline $1998-2000$ & $199,430(19.0)$ & $318(22.8)$ & - & - \\
\hline $200 I-2003$ & $194,023(18.5)$ & $292(20.9)$ & - & - \\
\hline 2004-2006 & 194,394 (18.5) & $282(20.2)$ & $172,024(32.1)$ & $\mathrm{I}, 058(55 . \mathrm{I})$ \\
\hline 2007-2009 & $193,196(18.4)$ & $180(12.9)$ & $181,039(33.8)$ & $695(36.2)$ \\
\hline $2010-2012$ & $63,712(6.1)$ & $38(2.7)$ & I82,475 (34.I) & $166(8.7)$ \\
\hline \multicolumn{5}{|l|}{ Sex } \\
\hline Male & $538,982(5 \mathrm{I} .4)$ & $496(35.6)$ & $275,138(5 \mid .4)$ & $738(38.5)$ \\
\hline Female & $510,651(48.7)$ & $899(64.4)$ & $260,400(48.6)$ & $\mathrm{I}, \mathrm{I8I}(6 \mathrm{I} .5)$ \\
\hline \multicolumn{5}{|l|}{ Birthweight } \\
\hline$\geq 4,500 \mathrm{~g}$ & $37,577(3.6)$ & $40(2.9)$ & $18,262(3.4)$ & 7I (3.7) \\
\hline $2,500-4,500 \mathrm{~g}$ & $948,3 \mid 7$ (9।.2) & $\mathrm{I}, 28 \mathrm{I}(92.4)$ & 490,946 (91.7) & I,78I (92.9) \\
\hline$<2,500 \mathrm{~g}$ & $53,46 I(5.1)$ & $65(4.7)$ & $26,074(4.9)$ & $66(3.4)$ \\
\hline Missing & 10,278 & 9 & 259 & $<5$ \\
\hline \multicolumn{5}{|l|}{ Gestational age } \\
\hline$<32$ weeks & $10,672(1.0)$ & $9(0.7)$ & $5,246(1.0)$ & $9(0.5)$ \\
\hline $32-36$ weeks & $57,212(5.5)$ & $54(3.9)$ & $30,043(5.7)$ & $98(5.1)$ \\
\hline $37-41$ weeks & $898,998(86.3)$ & $\mathrm{I}, 213(87.3)$ & $464,261(87.3)$ & I,690 (88.7) \\
\hline$\geq 42$ weeks & $75,289(7.2)$ & II $3(8.1)$ & $32,202(6.1)$ & $108(5.7)$ \\
\hline Missing & 7,462 & 6 & 3,786 & 14 \\
\hline \multicolumn{5}{|c|}{ Birthweight for gestational age } \\
\hline$\leq 10$ th percentile & $106,013(10.2)$ & $168(12.1)$ & $53,520(10.1)$ & $198(10.4)$ \\
\hline 10th-90th percentile & $823,670(79.4)$ & $\mathrm{I}, 098(79.3)$ & $424,522(79.9)$ & $1,514(79.5)$ \\
\hline$\geq 90$ th percentile & $107,376(10.4)$ & $118(8.5)$ & $53,625(10.1)$ & $192(10.1)$ \\
\hline Missing & 12,574 & II & 3,871 & 15 \\
\hline \multicolumn{5}{|l|}{ Parity } \\
\hline I & $460,031(44.2)$ & $616(44.3)$ & $225,639(42.1)$ & $825(43.0)$ \\
\hline 2 & $382,020(36.7)$ & $544(39.1)$ & $191,166(35.7)$ & $734(38.3)$ \\
\hline$\geq 3$ & $199,594(19.2)$ & $232(16.7)$ & $118,733(22.2)$ & $360(18.8)$ \\
\hline Missing & 7,988 & $<5$ & 0 & 0 \\
\hline \multicolumn{5}{|l|}{ Maternal education ${ }^{c}$} \\
\hline Compulsory education & $215,429(21.1)$ & $213(15.4)$ & 87,671 (17.1) & $207(10.9)$ \\
\hline Medium length & $493,81 I(48.4)$ & $697(50.4)$ & $153,439(29.9)$ & $515(27.0)$ \\
\hline Higher education & $310,861(30.5)$ & $474(34.3)$ & $272,827(53.1)$ & I,I $83(62.1)$ \\
\hline Missing & 29,532 & 11 & 21,601 & 14 \\
\hline \multicolumn{5}{|l|}{ Maternal age } \\
\hline$<20$ years & $16,470(1.6)$ & $12(0.9)$ & $11,364(2.1)$ & $31(1.6)$ \\
\hline $20-25$ years & $128,733(12.3)$ & $137(9.8)$ & $77,089(14.4)$ & $252(13.1)$ \\
\hline $25-30$ years & $362,335(34.5)$ & $531(38.1)$ & $166,816(31.2)$ & $669(34.9)$ \\
\hline $30-35$ years & $369,482(35.2)$ & $526(37.7)$ & $178,737(33.4)$ & $660(34.4)$ \\
\hline$\geq 35$ years & $172,598(16.4)$ & $189(13.6)$ & $101,532(19.0)$ & $307(16.0)$ \\
\hline Missing & 15 & $<5$ & 0 & 0 \\
\hline
\end{tabular}

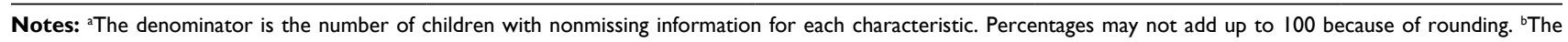
numbers for each type of cesarean section do not add up to the total number of cesarean sections because of missing data on the type of cesarean section. ${ }^{\circ}$ The classification of maternal education levels in Denmark and Norway is not straightforwardly comparable because of differences in the classification of education levels. Denmark: Compulsory education: 10 years. Medium length: additional 4 years of vocational education or 3 years of general education leading to a university admission certification possibly followed by I-2 years of further education. Higher education: education beyond medium length. Norway: Compulsory education: 10 years. Medium length: additional 4 years of vocational education or 3 years of general education leading to a university admission certification. Higher education: education beyond medium length. 
and included information on year of birth, sex, season of birth, gestational age, birthweight for gestational age and maternal age, education, parity, and history of diabetes (Norway) or autoimmune disease (Denmark), as well as mode of delivery and diagnosed celiac disease.

\section{Post hoc analyses}

The results from the separate analyses of the Danish and Norwegian cohorts were not completely consistent. Therefore, we carried out post hoc analyses in an attempt to explain the differences in the findings.

To test the effect of differences in the birth inclusion period, we standardized the inclusion period to births from 2004 to 2010 in both cohorts. To test the effect of differences in case definition, we standardized the case definition to one or more registrations and two or more registrations of celiac disease in the national patient registers. In the Danish cohort, we tested the association between mode of delivery and registration of celiac disease diagnoses that were not validated by duodenal biopsy or celiac disease-specific antibodies (which were most likely incorrect registrations), ${ }^{33}$ and the association between mode of delivery and registration of abdominal pain in the absence of registration of a gastrointestinal disease. Chronic abdominal pain may be the primary symptom in celiac disease, and therefore these children are likely to be screened for celiac disease increasing the risk of a diagnosis; thus, chronic abdominal pain may be a confounder for the association. Finally, we tested whether maternal request for elective cesarean section was associated with an increased risk of celiac disease because maternal request for elective cesarean section may be a proxy for health-seeking behavior.

\section{Ethics}

The Danish study was approved by the Danish Data Protection Agency. Patient consent from the participants and notification of the regional committees on health-research ethics were not required as this was a register-based study not including human biologic material, and the participants were not contacted (Health legislation $\$ 46.2$ and Legislation for Health-Research-Ethics and Health Science Research $\S 14.2)$.

The Norwegian study was approved by the Norwegian Data Inspectorate and by the Regional Committee for Medical and Health Research Ethics (2013/2114-12). The study was exempted from individual consent as this was a registerbased study with low risk of personal identification, and the participants were not contacted.

\section{Results}

For the analysis of the Danish cohort, we included 1,051,028 children born from January 1, 1995 to December 31, 2010 after exclusions for inconsistent data based on the personal identification numbers $(n=37)$. Celiac disease was registered for 1,395 children $(0.13 \%)$. The median age at diagnosis was 7.4 years (interquartile range: 4.3-11.2). Cesarean section was the mode of delivery for 196,248 children without celiac disease (18.9\%) and for 264 children with celiac disease (19.1\%).

For the analysis of the Norwegian cohort, we included 537,457 children born from January 1, 2004 to December 31, 2012 after exclusions for inconsistent data based on the personal identification numbers $(n=3,579)$. For each child, the date of birth was set to 15 th in the registered month of birth. Celiac disease was registered for 1,919 children $(0.35 \%)$. Cesarean section was the mode of delivery for 89,840 children without celiac disease $(16.8 \%)$ and for 288 children with celiac disease $(15.0 \%)$.

Table 1 shows the distribution of potential confounders according to celiac disease diagnosis.

\section{Main analyses}

We found no significant association between the mode of delivery and the risk of celiac disease (Table 2). However, in the Danish cohort, the association between elective cesarean section and diagnosed celiac disease was positive and reached borderline statistical significance after adjusting for year of birth, sex, maternal age, education, parity, gestational age, and weight for gestational age (OR: 1.20; 95\% CI: 1.00-1.43). This finding was not replicated in the Norwegian cohort (OR: 0.96; 95\% CI: 0.79-1.17) (Table 2).

\section{Sensitivity analysis}

Sensitivity analyses involving adjustment for potential confounders that were only available in the Danish cohort (maternal country of birth, maternal prepregnancy BMI, and maternal autoimmune diseases diagnosed before the birth of the child) did not change the conclusions (Table 3 ). Similarly, stratification for age at diagnosis $(<2$ or $\geq 2$ years of age) and the presence of an associated comorbidity did not change the conclusions (Table 4). Furthermore, multiple imputation for missing data in models $1-3$ and model 3 with adjustment for smoking did not change the conclusions (Table 5). In addition, analysis of the Danish data using a Cox regression model did not change the conclusions (data not shown). 
Table 2 Association between mode of delivery and risk of celiac disease (main analyses)

\begin{tabular}{|c|c|c|c|c|}
\hline Mode of delivery & Model Ia, OR $(95 \% \mathrm{Cl})$ & Model $2^{\mathrm{b}}$, OR $(95 \% \mathrm{Cl})$ & Model 3c, OR (95\% Cl) & Smoking ${ }^{\mathrm{d}}$, OR $(95 \% \mathrm{Cl})$ \\
\hline Denmark $(n=I, 000,754)$ & & & & $(n=963,607)$ \\
\hline Vaginal delivery & I.00 (Ref) & $\mathrm{I} .00$ (Ref) & $\mathrm{I} .00$ (Ref) & $\mathrm{I} .00$ (Ref) \\
\hline Cesarean section & $1.06(0.92-1.22)$ & $1.07(0.93-1.24)$ & I.II (0.96-I.29) & $1.10(0.95-1.27)^{\mathrm{b}}$ \\
\hline Emergency ${ }^{e}$ & $1.00(0.82-1.22)$ & $1.00(0.82-1.22)$ & $1.02(0.83-1.26)$ & $1.00(0.8 \mathrm{I}-1.23)^{\mathrm{b}}$ \\
\hline Elective $^{\mathrm{e}}$ & $1.12(0.94-1.34)$ & $1.14(0.95-1.36)$ & $1.20(1.00-1.43)$ & $1.20(1.00-1.44)^{\mathrm{b}}$ \\
\hline Norway $(n=5 \mid 2,253)$ & & & & $(n=427,409)$ \\
\hline Vaginal delivery & I.00 (Ref) & $\mathrm{I} .00$ (Ref) & $\mathrm{I} .00$ (Ref) & $\mathrm{I} .00$ (Ref) \\
\hline Cesarean section & $0.90(0.79-1.03)$ & $0.93(0.82-1.06)$ & $0.96(0.84-1.09)$ & $1.02(0.88-1.17)^{\mathrm{b}}$ \\
\hline Emergency & $0.90(0.76-1.06)$ & $0.92(0.78-1.09)$ & $0.96(0.81-1.14)$ & $0.98(0.82-1.18)^{b}$ \\
\hline Elective & $0.92(0.76-1.11)$ & $0.96(0.79-1.16)$ & $0.96(0.79-1.17)$ & $1.07(0.87-1.3 \mathrm{I})^{\mathrm{b}}$ \\
\hline Pooled $(n=1,5 \mid 3,007)$ & & & & $(n=1,391,016)$ \\
\hline Vaginal delivery & $\mathrm{I} .00$ (Ref) & $\mathrm{I} .00$ (Ref) & $\mathrm{I} .00$ (Ref) & $\mathrm{I} .00$ (Ref) \\
\hline Cesarean section & $0.98(0.91-1.04)$ & $1.00(0.93-1.07)$ & $1.03(0.96-1.10)$ & $1.05(0.98-1.13)$ \\
\hline Emergency ${ }^{\mathrm{e}}$ & $0.94(0.86-1.03)$ & $0.95(0.87-1.04)$ & $0.99(0.90-1.08)$ & $1.03(0.93-1.14)$ \\
\hline Elective $^{\mathrm{e}}$ & $1.02(0.93-1.12)$ & $1.05(0.96-1.15)$ & $1.08(0.98-1.18)$ & $1.08(0.99-1.19)$ \\
\hline
\end{tabular}

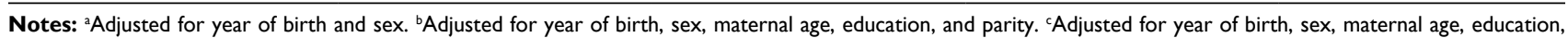
parity, gestational age, and weight for gestational age. 'Adjusted for year of birth, sex, maternal age, education, parity, gestational age, weight for gestational age, and smoking. eThe numbers for each type of cesarean section do not add up to the total number of cesarean sections because of missing data on the type of cesarean section. Abbreviations: $\mathrm{Cl}$, confidence interval; OR, odds ratio.

Table 3 Effect of adjustment for confounders that were only available for the Danish cohort

\begin{tabular}{|c|c|c|c|c|}
\hline Mode of delivery & $\begin{array}{l}\text { Model 3 } 3^{a}, \text { OR }(95 \% \\
\text { CI) }(n=1,000,754)\end{array}$ & $\begin{array}{l}\text { Maternal prepregnancy } \\
\text { BMIb, OR }(95 \% \mathrm{Cl}) \\
(\mathrm{n}=402,72 \mathrm{I})\end{array}$ & $\begin{array}{l}\text { Maternal country of } \\
\text { birthc }^{c} \text { OR }(95 \% \mathrm{CI}) \\
(\mathrm{n}=\mathrm{I}, 000,566)\end{array}$ & $\begin{array}{l}\text { Maternal autoimmune } \\
\text { disease }^{\mathrm{d}, \mathrm{e}}, \text { OR }(95 \% \mathrm{Cl}) \\
(\mathrm{n}=\mathrm{I}, 000,586)\end{array}$ \\
\hline Vaginal delivery & $\mathrm{I} .00$ (Ref) & $\mathrm{I} .00$ (Ref) & I.00 (Ref) & I.00 (Ref) \\
\hline Cesarean section & $1.10(0.96-1.28)$ & $0.99(0.79-1.25)^{c}$ & $1.11(0.97-1.29)^{d}$ & $1.09(0.95-1.26)^{f}$ \\
\hline Emergency & $1.02(0.83-1.25)$ & $0.77(0.53-1.11)^{c}$ & $1.04(0.84-1.27)^{d}$ & $1.02(0.83-1.25)^{f}$ \\
\hline Elective & $1.19(1.00-1.42)$ & $1.17(0.90-1.53)^{c}$ & $1.19(0.99-1.42)^{d}$ & $1.17(0.98-1.39)^{f}$ \\
\hline
\end{tabular}

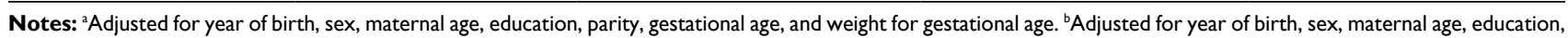
parity, gestational age, weight for gestational age, and maternal prepregnancy BMI. 'Adjusted for year of birth, sex, maternal age, education, parity, gestational age, weight for gestational age, and maternal country of birth. ${ }^{~ A d j u s t e d ~ f o r ~ y e a r ~ o f ~ b i r t h, ~ s e x, ~ m a t e r n a l ~ a g e, ~ e d u c a t i o n, ~ p a r i t y, ~ g e s t a t i o n a l ~ a g e, ~ w e i g h t ~ f o r ~ g e s t a t i o n a l ~ a g e, ~ a n d ~ m a t e r n a l ~}$ autoimmune disease diagnosed before the birth of the child. 'Before giving birth, the mother was registered in the Danish National Patient Register with a diagnosis of thyroid disease (ICD- I0: E050 E063 O0992B O992C), rheumatoid arthritis (ICD-I0: M05 M06), type I diabetes (ICD-I0: EI0 O240), or celiac disease (ICD- I0: K90.0).

Abbreviations: BMI, body mass index; Cl, confidence interval; ICD-I0, International Classification of Diseases I0th revision; OR, odds ratio.

Table 4 Effect of stratification on celiac disease diagnosis before or after 2 years of age and presence of a diagnosed associated comorbidity (data from Denmark)

\begin{tabular}{|c|c|c|c|c|}
\hline Mode of delivery & $\begin{array}{l}<2 \text { years olda, } \\
\text { OR }(95 \% \mathrm{Cl})\end{array}$ & $\begin{array}{l}\geq 2 \text { years olda, } \\
\text { OR }(95 \% \mathrm{Cl})\end{array}$ & $\begin{array}{l}\text { Associated } \\
\text { comorbidity }{ }^{\mathrm{a}, \mathrm{b}} \text {, } \\
\text { OR }(95 \% \mathrm{Cl})\end{array}$ & $\begin{array}{l}\text { No associated } \\
\text { comorbidity } \\
\text { OR }(95 \% \mathrm{Cl})\end{array}$ \\
\hline Vaginal delivery & 1.00 (Ref) & 1.00 (Ref) & 1.00 (Ref) & 1.00 (Ref) \\
\hline Cesarean section & $1.23(0.78-1.95)$ & $1.10(0.95-1.28)$ & $1.33(0.92-1.91)$ & $1.07(0.91-1.25)$ \\
\hline Emergency & $1.22(0.64-2.31)$ & $1.00(0.8 I-1.24)$ & $1.36(0.84-2.2 I)$ & $0.97(0.78-1.22)$ \\
\hline Elective & $1.25(0.69-2.31)$ & $1.19(0.99-1.43)$ & $1.30(0.82-2.08)$ & $1.16(0.96-1.4 I)$ \\
\hline
\end{tabular}

Notes: ${ }^{\mathrm{A} A d j u s t e d ~ f o r ~ y e a r ~ o f ~ b i r t h, ~ s e x, ~ m a t e r n a l ~ a g e, ~ e d u c a t i o n, ~ p a r i t y, ~ g e s t a t i o n a l ~ a g e, ~ a n d ~ w e i g h t ~ f o r ~ g e s t a t i o n a l ~ a g e . ~}{ }^{\mathrm{b}}$ The child is registered in the Danish National Patient Register with a diagnosis of type I diabetes (ICD-I0: EIO, EI4), autoimmune thyroid disease (ICD-10: E039, E05, E063), autoimmune hepatitis (ICD-I0: K754, K732), juvenile rheumatoid arthritis (ICD-10: M080), Down's syndrome (ICD-10: Q90), or Turner's syndrome (ICD-10: Q96).

Abbreviations: $\mathrm{Cl}$, confidence interval; ICD- I0, International Classification of Diseases I0th revision; OR, odds ratio.

\section{Post hoc analyses}

Post hoc analyses involving the restriction of the birth period to 2004-2010 and standardization of the outcome definition to one or more registrations of celiac disease or two or more registrations of celiac disease did not change the conclusions
(Table 6). We found a significant association between elective cesarean section and registration of a celiac disease diagnosis that was not validated by duodenal biopsies or celiac disease-specific antibodies, that is, most likely an incorrect registration ${ }^{33}$ (OR: 1.46; 95\% CI: 1.16-1.83; Table 7). 
Table 5 Effect of multiple imputation for missing data

\begin{tabular}{|c|c|c|c|c|}
\hline Mode of delivery & Model I ${ }^{a}$, OR $(95 \% \mathrm{CI})$ & Model $2^{\mathrm{b}}$, OR $(95 \% \mathrm{Cl})$ & Model 3c, OR (95\% Cl) & Smoking ${ }^{\mathrm{d}}$, OR $(95 \% \mathrm{Cl})$ \\
\hline \multicolumn{5}{|c|}{ Denmark $(n=I, 05 I, 028)$} \\
\hline Vaginal delivery & $\mathrm{I} .00$ (Ref) & 1.00 (Ref) & 1.00 (Ref) & 1.00 (Ref) \\
\hline Cesarean section & $\mathrm{I} .06(0.92-1.22)$ & $1.05(0.9|-| .2 I)$ & $1.09(0.95-1.26)$ & $1.10(0.95-1.26)$ \\
\hline Emergency & $1.00(0.83-1.22)$ & $0.98(0.80-1.20)$ & I.0I (0.82-I.24) & $1.01(0.82-1.24)$ \\
\hline Elective & I.II (0.93-I.32) & $1.12(0.94-1.33)$ & I. $17(0.98-1.40)$ & I.I $8(0.98-1.40)$ \\
\hline \multicolumn{5}{|c|}{ Norway $(n=537,457)$} \\
\hline Vaginal delivery & I.00 (Ref) & I.00 (Ref) & I.00 (Ref) & I.00 (Ref) \\
\hline Cesarean section & $0.90(0.79-1.02)$ & $0.93(0.81-1.05)$ & $0.95(0.83-1.08)$ & $0.95(0.83-1.08)$ \\
\hline Emergency & $0.92(0.76-I . I I)$ & $0.96(0.79-1.16)$ & $0.96(0.79-1.16)$ & $0.96(0.79-1.16)$ \\
\hline Elective & $0.88(0.75-1.04)$ & $0.90(0.77-1.06)$ & $0.93(0.79-1.09)$ & $0.93(0.79-1.09)$ \\
\hline
\end{tabular}

Notes: adjusted for year of birth and sex. ${ }^{b}$ Adjusted for year of birth, sex, maternal age, education, and parity. ${ }^{\mathrm{A} A d j u s t e d}$ for year of birth, sex, maternal age, education, parity, gestational age, and weight for gestational age. ${ }^{\mathrm{d}}$ Adjusted for year of birth, sex, maternal age, education, parity, gestational age, weight for gestational age, and smoking. Abbreviations: $\mathrm{Cl}$, confidence interval; OR, odds ratio.

Table 6 Effect of restricting the birth period to 2004-2010 and standardization of outcome definition

\begin{tabular}{|c|c|c|c|c|c|c|}
\hline \multirow[t]{3}{*}{ Mode of delivery } & \multicolumn{2}{|c|}{$\begin{array}{l}\text { Birth period restricted to } \\
2004-2010^{\mathrm{a}}, \text { OR }(95 \% \mathrm{Cl})\end{array}$} & \multicolumn{4}{|c|}{ Standardization of outcome definition ${ }^{\mathrm{a}}$, OR $(95 \% \mathrm{CI})$} \\
\hline & \multirow{2}{*}{$\begin{array}{l}\text { Denmark } \\
(n=429,675)\end{array}$} & \multirow{2}{*}{$\begin{array}{l}\text { Norway } \\
(n=398,070)\end{array}$} & \multicolumn{2}{|c|}{ Denmark $(n=I, 000,754)$} & \multicolumn{2}{|c|}{ Norway $(n=5 \mid 2,253)$} \\
\hline & & & $\geq I$ registration & $\geq 2$ registrations & $\geq I$ registration & $\geq 2$ registrations \\
\hline Vaginal delivery & 1.00 (Ref) & I.00 (Ref) & 1.00 (Ref) & 1.00 (Ref) & 1.00 (Ref) & 1.00 (Ref) \\
\hline Cesarean section & $1.02(0.81-1.28)$ & $0.95(0.83-1.08)$ & $1.14(1.02-1.29)$ & I.II (0.97-I.26) & $1.01(0.90-1.13)$ & $0.96(0.84-1.09)$ \\
\hline Emergency & $0.81(0.56-1.15)$ & $0.94(0.79-1.12)$ & $1.00(0.84-1.19)$ & $0.99(0.82-1.20)$ & $1.02(0.88-1.18)$ & $0.96(0.81-1.14)$ \\
\hline Elective & $1.19(0.92-1.55)$ & $0.96(0.79-1.17)$ & $1.27(1.10-1.47)$ & $1.20(\mid .02-1.4 I)$ & $0.99(0.84-1.17)$ & $0.96(0.79-1.17)$ \\
\hline
\end{tabular}

Notes: adjusted for year of birth, sex, maternal age, education, parity, gestational age, and weight for gestational age.

Abbreviations: $\mathrm{Cl}$, confidence interval; $\mathrm{OR}$, odds ratio.

Table 7 Associations between mode of delivery and registration of celiac disease diagnosis that could not be validated and registration of abdominal pain in the absence of a gastrointestinal diagnosis (Danish data)

\begin{tabular}{|c|c|c|c|c|}
\hline \multirow[t]{2}{*}{ Mode of delivery } & \multicolumn{2}{|c|}{$\begin{array}{l}\text { Unvalidated celiac disease registration }{ }^{a}, \text { OR } \\
(95 \% \mathrm{CI})(\mathrm{n}=1,000,754[737 \text { cases }])\end{array}$} & \multicolumn{2}{|c|}{$\begin{array}{l}\text { Abdominal pain }{ }^{b} \text {, no gastrointestinal diagnosis }{ }^{c}, \text { OR } \\
(95 \% \mathrm{CI})(\mathrm{n}=1,000,754[22,0 \mathrm{I} 5 \text { cases }])\end{array}$} \\
\hline & Model Id & Model 3e & Model Id & Model 3e \\
\hline Vaginal delivery & I.00 (Ref) & I.00 (Ref) & I.00 (Ref) & $\mathrm{I} .00$ (Ref) \\
\hline Cesarean section & $1.20(1.00-1.43)$ & $1.21(1.01-1.46)$ & $1.06(1.02-1.10)$ & $1.07(I .03-1.11)$ \\
\hline Emergency & 0.91 (0.69-I.19) & $0.92(0.70-1.22)$ & 1.07 (I.02-I.I2) & $1.06(1.01-1.11)$ \\
\hline Elective & $1.44(1.16-1.79)$ & $1.46(1.16-1.83)$ & $1.05(1.01-1.10)$ & $1.08(1.03-1.13)$ \\
\hline
\end{tabular}

Notes: ${ }^{2}$ One or more registrations in the Danish National Patient Register excluding diagnoses that were validated, ${ }^{33}$ most likely a false registration of celiac disease. ${ }^{33}$ ${ }^{b}$ Registration of abdominal pain (ICD- I0: RI0I, R I03, R I04, R I08) in the Danish National Patient Register. 'Registration of gastrointestinal disease (ICD- I0: K*) in the Danish National Patient Register. ${ }^{\mathrm{d} A d j u s t e d}$ for year of birth and sex. ${ }^{\mathrm{e} A d j u s t e d ~ f o r ~ y e a r ~ o f ~ b i r t h, ~ s e x, ~ m a t e r n a l ~ a g e, ~ e d u c a t i o n, ~ p a r i t y, ~ g e s t a t i o n a l ~ a g e, ~ a n d ~ w e i g h t ~ f o r ~ g e s t a t i o n a l ~ a g e . ~}$

Abbreviations: $\mathrm{Cl}$, confidence interval; ICD-I0, International Classification of Diseases I0th revision; OR, odds ratio.

Additionally, we found an association between cesarean section and registration of abdominal pain in the absence of registration of a gastrointestinal disease (OR: 1.08; 95\% CI: 1.03-1.13; Table 7).

Registration of a maternal request for an elective cesarean section increased from 196 of 6,880 elective cesarean sections in $2002(2.9 \%)$ to 1,572 of 7,885 elective cesarean sections in 2010 (19.9\%). Maternal request for an elective cesarean section was not associated with celiac disease compared to elective cesarean sections for other reasons (OR: 0.91; 95\% CI: 0.51-1.62).

\section{Discussion}

In this large study of two independent national cohorts, we found no association between the mode of delivery and risk of diagnosed celiac disease.

A positive albeit not statistically significant association between elective cesarean section and celiac disease was found in the Danish cohort. We cannot preclude that this is a confirmation of previous findings. ${ }^{15}$ However, post hoc exploration of this association indicated that it was most likely attributable to factors other than celiac disease per se. The association did not increase with more strict case definitions but was 
statistically significant for registrations of celiac disease that was not validated (most likely incorrect registrations). This is contrary to what we would expect to find if elective cesarean section was truly associated with celiac disease. Furthermore, we found an association between elective cesarean section and registration of abdominal pain in the absence of registration of a gastrointestinal disease. This suggests that the seeming association between elective cesarean section and diagnosed celiac disease may be explained by an association with registered symptoms that lead to the suspicion of celiac disease, including abdominal pain. This association could be caused by differences in health-seeking behavior, biologic mechanisms, or other factors. It can be speculated that children referred to a hospital for chronic abdominal pain are more likely to be screened for celiac disease and thus more likely to be diagnosed. This would lead to a higher proportion of diagnosed celiac disease cases and thus bias the results toward a positive association, as our study only includes diagnosed cases of celiac disease. Maternal request for an elective cesarean section may be a proxy for differences in health-seeking behavior but was not associated with celiac disease compared to elective cesarean section for other reasons. However, the number of children included in this analysis was small and consequently the $95 \%$ CI was wide.

Previous studies have found inconsistent results on the association between cesarean section and celiac disease. ${ }^{9}$ One study reported a positive association between all types of cesarean section and celiac disease (OR: 1.83; 95\% CI: $1.18-2.85),{ }^{12}$ and a large Swedish study of more than 11,000 celiac disease cases found a small but significant association between elective cesarean section and celiac disease (OR: 1.15; 95\% CI: 1.04-1.26). ${ }^{15}$ Another Swedish study found no association between all types of cesarean sections and celiac disease, although the authors did find an association in children with both celiac disease and type 1 diabetes mellitus (OR: 1.60; 95\% CI: 1.07-1.39).${ }^{18}$ A third Swedish study reported no association in the main analysis but found a borderline significant association for boys in a multivariate analysis (OR: 1.2; 95\% CI: $1.0-1.4) .{ }^{14}$ One small study from southern England reported a nonsignificantly decreased risk of celiac disease for those born by cesarean section (OR: 0.29; 95\% CI: 0.07-1.17). ${ }^{16}$ Large observational cohort studies from Norway ${ }^{13}$, Italy, ${ }^{19}$ and Denmark ${ }^{17}$ found no association between all types of cesarean section and celiac disease. The Norwegian ${ }^{13}$ and Italian ${ }^{19}$ studies also showed that there was no association between elective cesarean section and celiac disease. A multinational birth cohort (the TEDDY study) has recently reported no association between mode of delivery and risk of celiac disease autoimmunity. ${ }^{20}$ Overall, the evidence seems to point toward no association. ${ }^{9}$ However, this remains to be confirmed in a systematic review and meta-analysis. ${ }^{15}$

It has been proposed that the frequently observed inconsistencies between Swedish and non-Swedish studies may be explained by country-specific risk factors. ${ }^{9}$ However, the Swedish results themselves are ambiguous. Differences in findings between studies may be caused by differences in case definition and registration, but there does not seem to be a systematic trend in the studies. Differences may also be attributed to differences in the study setting, including the prevalence of cesarean section and possibly differences in perinatal procedures, for example, the use and timing of antibiotics, hospitalization, and infant feeding. These practices are likely to differ between countries and even within countries, and to change over time. This has not been addressed specifically in any of the studies.

The studies differ in terms of adjustment for potential confounders. However, except for one study, ${ }^{14}$ the adjustment for potential confounders did not seem to change the conclusions, which was also the case in our study. As with all observational studies, a limitation of this study is the risk of residual confounding. We used registrations of diagnosed celiac disease as our outcome. This may increase the risk of bias because unmeasured confounders, such as health-seeking behavior, may be associated with the mode of delivery and the likelihood of being diagnosed as compared to remaining undiagnosed. We included relevant confounders that were suggested and used in previous studies and available for this study. However, the literature on confounders is ambiguous and the risk factors for celiac disease remain largely unknown. Thus, it is likely that potential confounders are yet to be discovered and therefore not accounted for in this study. These could influence our findings in both directions. An example that was previously discussed in this study is the association between mode of delivery and registration of abdominal pain in the absence of gastrointestinal disease that may bias the results toward a positive association. It is possible that such a bias could affect many observational studies on the impact of cesarean section on subsequent disease in the offspring.

In conclusion, we found that the mode of delivery was not associated with an increased risk of diagnosed celiac disease. Other studies have found inconsistent conclusions but there seems to be limited evidence of an association. Thus, we found no evidence to support the hypothesis that exposure to maternal vaginal and fecal microbiota during birth reduces the risk of celiac disease. 


\section{Acknowledgments}

This study was funded by the Novo Nordisk Foundation, the A.P. Møller Foundation, and Odense University Hospital's $\mathrm{PhD}$ grant. KS is supported by an unrestricted grant from OAK Foundation, Geneva, Switzerland.

\section{Disclosure}

The authors report no conflicts of interest in this work.

\section{References}

1. Husby S, Koletzko S, Korponay-Szabo IR, et al; European Society for Pediatric Gastroenterology, Hepatology, and Nutrition. European society for pediatric gastroenterology, hepatology, and nutrition guidelines for the diagnosis of coeliac disease. J Pediatr Gastroenterol Nutr. 2012;54(1):136-160.

2. Rubio-Tapia A, Kyle RA, Kaplan EL, et al. Increased prevalence and mortality in undiagnosed celiac disease. Gastroenterology. 2009;137(1): 88-93.

3. Choung RS, Ditah IC, Nadeau AM, et al. Trends and racial/ethnic disparities in gluten-sensitive problems in the United States: findings from the National Health and Nutrition Examination Surveys from 1988 to 2012. Am J Gastroenterol. 2015;110(3):455-461.

4. Myleus A, Ivarsson A, Webb C, et al. Celiac disease revealed in 3\% of Swedish 12-year-olds born during an epidemic. J Pediatr Gastroenterol Nutr. 2009;49(2):170-176.

5. Lohi S, Mustalahti K, Kaukinen K, et al. Increasing prevalence of coeliac disease over time. Aliment Pharmacol Ther. 2007;26(9):1217-1225.

6. Sollid LM, Markussen G, Ek J, Gjerde H, Vartdal F, Thorsby E. Evidence for a primary association of celiac disease to a particular HLA-DQ alpha/beta heterodimer. J Exp Med. 1989;169(1):345-350.

7. Madsen M, Svejgaard A, Graugaard B, et al. HLA-B, -DR haplotype frequencies and gametic association in 1,204 unrelated Danes. Tissue Antigens. 1981;18(4):276-279.

8. Ludvigsson JF, Green PH. The missing environmental factor in celiac disease. N Engl J Med. 2014;371(14):1341-1343.

9. Marild K, Ludvigsson JF, Stordal K. Current evidence on whether perinatal risk factors influence coeliac disease is circumstantial. Acta Paediatr. 2016;105(4):366-375.

10. Pinto-Sanchez MI, Verdu EF, Liu E, et al. Gluten introduction to infant feeding and risk of celiac disease: systematic review and meta-analysis. J Pediatr. 2016;168:132-143.

11. Betran AP, Ye J, Moller AB, Zhang J, Gulmezoglu AM, Torloni MR. The increasing trend in caesarean section rates: global, regional and national estimates: 1990-2014. PLoS One. 2016;11(2):e0148343.

12. Decker E, Engelmann G, Findeisen A, et al. Cesarean delivery is associated with celiac disease but not inflammatory bowel disease in children Pediatrics. 2010;125(6):e1433-e1440.

13. Emilsson L, Magnus MC, Stordal K. Perinatal risk factors for development of celiac disease in children, based on the prospective Norwegian Mother and Child Cohort Study. Clin Gastroenterol Hepatol. 2015;13(5):921-927.

14. Namatovu F, Olsson C, Lindkvist M, et al. Maternal and perinatal conditions and the risk of developing celiac disease during childhood. BMC Pediatr. 2016;16(1):77.

15. Marild K, Stephansson O, Montgomery S, Murray JA, Ludvigsson JF. Pregnancy outcome and risk of celiac disease in offspring: a nationwide case-control study. Gastroenterology. 2012;142(1):39-45 e33.

16. Roberts SE, Williams JG, Meddings D, Davidson R, Goldacre MJ. Perinatal risk factors and coeliac disease in children and young adults: a record linkage study. Aliment Pharmacol Ther. 2009;29(2):222-231.
17. Sevelsted A, Stokholm J, Bonnelykke K, Bisgaard H. Cesarean section and chronic immune disorders. Pediatrics. 2015;135(1):e92-e98.

18. Adlercreutz EH, Wingren CJ, Vincente RP, Merlo J, Agardh D. Perinatal risk factors increase the risk of being affected by both type 1 diabetes and coeliac disease. Acta Paediatr. 2015;104(2):178-184.

19. Canova C, Zabeo V, Pitter G, et al. Association of maternal education, early infections, and antibiotic use with celiac disease: a population-based birth cohort study in northeastern Italy. Am J Epidemiol. 2014;180(1):76-85.

20. Koletzko S, Lee HS, Beyerlein A, et al. Caesarean section on the risk of celiac disease in the offspring: The Teddy Study. J Pediatr Gastroenterol Nutr. Epub 2017 Jul 27.

21. Rutayisire E, Huang K, Liu Y, Tao F. The mode of delivery affects the diversity and colonization pattern of the gut microbiota during the first year of infants' life: a systematic review. BMC Gastroenterol. 2016;16(1):86.

22. McLean MH, Dieguez D Jr, Miller LM, Young HA. Does the microbiota play a role in the pathogenesis of autoimmune diseases? Gut. 2015;64(2):332-341.

23. Collado MC, Donat E, Ribes-Koninckx C, Calabuig M, Sanz Y. Specific duodenal and faecal bacterial groups associated with paediatric coeliac disease. J Clin Pathol. 2009;62(3):264-269.

24. Nadal I, Donat E, Ribes-Koninckx C, Calabuig M, Sanz Y. Imbalance in the composition of the duodenal microbiota of children with coeliac disease. J Med Microbiol. 2007;56(Pt 12):1669-1674.

25. Losurdo G, Principi M, Iannone A, Ierardi E, Di Leo A. The interaction between celiac disease and intestinal microbiota. J Clin Gastroenterol. 2016;50(Suppl 2): Proceedings from the 8th Probiotics, Prebiotics \& New Foods for Microbiota and Human Health meeting held in Rome, Italy on September 13-15, 2015:S145-S147.

26. Kostic AD, Gevers D, Siljander H, et al. The dynamics of the human infant gut microbiome in development and in progression toward type 1 diabetes. Cell Host Microbe. 2015;17(2):260-273.

27. Arrieta MC, Stiemsma LT, Dimitriu PA, et al. Early infancy microbial and metabolic alterations affect risk of childhood asthma. Sci Transl Med. 2015;7(307):307ra152.

28. Rusconi F, Zugna D, Annesi-Maesano I, et al. Mode of delivery and asthma at school age in 9 European Birth Cohorts. Am J Epidemiol. 2017;185(6):465-473

29. Emilsson L, Magnus MC, Stordal K. Perinatal risk factors for development of celiac disease in children, based on the prospective Norwegian Mother and Child Cohort Study. Clin Gastroenterol Hepatol. 2015;13(5): 921-927.

30. Pedersen CB. The Danish Civil Registration System. Scand J Public Health. 2011;39(7 Suppl):22-25.

31. Lynge E, Sandegaard JL, Rebolj M. The Danish National Patient Register. Scand J Public Health. 2011;39(7 Suppl):30-33.

32. Schmidt M, Schmidt SA, Sandegaard JL, Ehrenstein V, Pedersen L, Sorensen HT. The Danish National Patient Registry: a review of content, data quality, and research potential. Clin Epidemiol. 2015;7:449-490.

33. Dydensborg Sander S, Stordal K, Plato Hansen T, et al. Validation of celiac disease diagnoses recorded in the Danish National Patient Register using duodenal biopsies, celiac disease-specific antibodies, and human leukocyte-antigen genotypes. Clin Epidemiol. 2016;8:789-799.

34. Knudsen LB, Olsen J. The Danish Medical Birth Registry. Dan Med Bull. 1998;45(3):320-323.

35. Jensen VM, Rasmussen AW. Danish Education Registers. Scand J Public Health. 2011;39(7 Suppl):91-94.

36. Varmdal T, Bakken IJ, Janszky I, et al. Comparison of the validity of stroke diagnoses in a medical quality register and an administrative health register. Scand J Public Health. 2016;44(2):143-149.

37. Irgens LM. The Medical Birth Registry of Norway. Epidemiological research and surveillance throughout 30 years. Acta Obstet Gynecol Scand. 2000;79(6):435-439.

38. White IR, Royston P, Wood AM. Multiple imputation using chained equations: issues and guidance for practice. Stat Med. 2011;30(4):377-399. 


\section{Publish your work in this journal}

Clinical Epidemiology is an international, peer-reviewed, open access, online journal focusing on disease and drug epidemiology, identification of risk factors and screening procedures to develop optimal preventative initiatives and programs. Specific topics include: diagnosis, prognosis, treatment, screening, prevention, risk factor modification,

Submit your manuscript here: https://www.dovepress.com/clinical-epidemiology-journa systematic reviews, risk and safety of medical interventions, epidemiology and biostatistical methods, and evaluation of guidelines, translational medicine, health policies and economic evaluations. The manuscript management system is completely online and includes a very quick and fair peer-review system, which is all easy to use. 